\title{
Association of BMI on Systolic and Diastolic Blood Pressure In Normal and
}

\section{Obese Children}

\author{
Gundogdu $\mathbf{Z}^{1}$
}

${ }^{1}$ Specialist in child and health diseases, Kocaeli Metropolitan Municipality Maternity and Children Hospital,

Kocaeli, 41028, Turkey

\section{Original Article}

\section{Corresponding Author:}

\section{Dr. Zuhal Gundogdu}

Specialist in child and health diseases, Kocaeli Metropolitan Municipality Maternity and Children Hospital, Kocaeli, 41028, Turkey

Email: $\underline{\text { z.gundo@gmail.com }}$

\section{Abstract}

\section{Background}

Definition of childhood overweight/obesity should aim to identify children with excess body fat in order to treat the associated adverse health outcomes.

\section{Objective}

To investigate relationship between Body Mass Index (BMI) and systolic blood pressure (SBP) and diastolic blood pressure (DBP) values in children between the ages of 6 and 14 year old.

\section{Materials and Methods}

Secondary data gathered from public health screening days at Child Health and Diseases Polyclinic of Kocaeli Metropolitan Municipality Maternity and Children Hospital on 1899 children. Each child was classified on the basis of age- and sex-specific Body Mass Index percentile (BMI\%) as normal weight $\left(\mathrm{BMI} \%<85^{\text {th }}\right)$, overweight $\left(\mathrm{BMI} \% \geq 85^{\text {th }}\right.$ and $<$ $\left.95^{\text {th }}\right)$, or obese $\left(\mathrm{BMI} \% \geq 95^{\text {th }}\right)$. Systolic and diastolic blood pressures were compared among age-sex-BMI percentile groups.

\section{Results}

SBP and DBP values are higher in obese and overweight children compared to normal children. Among all children in this study, being overweight and obese increased the likelihood of elevated SBP and DBP values after adjusting for age. Blood pressure (BP) is increasing with increasing $\mathrm{BMI}$ in all age groups ( 6 to 14 year old) and this is also found at a young age. The same trend is also present within the normal BMI\% group.

\section{Conclusions}

Our results show that BMI is associated with elevated systolic and diastolic blood pressure in overweight and obese children as well as children in normal BMI\% group. BP is increasing with increasing BMI values even in normal group but the increase is more in obese children. Hence, maintaining age related normal growth increase in the BMI in childhood is important in preventing higher BP values later in life.

Keywords: Body Mass Index, Blood pressure, Children

\section{Background}

The worldwide increase of prevalence of obesity in childhood and adolescence poses an ever-increasing problem ${ }^{1}$ as obesity is turning into a serious public health issue $e^{2,3}$. Many of the outcomes associated with obesity that was previously thought of as diseases of adults are now affecting children ${ }^{4-6}$.

The association between overweight and hypertension in children has been reported in a variety of ethnic and racial groups, with virtually all studies finding higher blood pressures and/or higher prevalences of hypertension in overweight children compared with normal children ${ }^{7}$. It is reported that obesity is one of the main effectors of BP in children $^{8,9}$.

There is a great deal of interest in defining and measuring adiposity and body composition among children and general consensus is that an age-related BMI should be used, since 
it is significantly associated with body fatness in children and adolescents ${ }^{10,11}$.

Definition of childhood overweight/obesity should aim to identify children with excess body fat in order to treat the associated adverse health outcomes. At the population level, this should help identify children at higher risk of developing the adverse consequences of obesity in order to implement early preventive strategies against disease. Whilst clear-cut definitions of overweight and obesity are available for the adult population, child growth adds a dynamic component that complicates the definition of these conditions ${ }^{12}$.

Overweight and obesity were defined according to the recommendations of the International Obesity Task Force, IOTF, using international reference values based on data from six countries. These age and sex specific BMI cut-off points for overweight and obesity in children (between 2 and 18 years) were constructed using dataset specific centiles corresponding to the widely accepted adult cutpoints of a BMI of $25 \mathrm{~kg} / \mathrm{m} 2$ (overweight) and $30 \mathrm{~kg} / \mathrm{m} 2$ (obesity) ${ }^{13}$.

For children and adolescents in the clinical setting, BMI percentiles are recommended by the Centres for Disease Control and Prevention (CDC) 2000 standard $^{14}$. Children with $\mathrm{BMI} \%$ values between $85^{\text {th }}$ and $95^{\text {th }}(\geq 85 \%-<95 \%)$ are considered as overweight and $95^{\text {th }}$ or above $(\geq 95 \%)$ as obese. Children and adolescents can be defined as overweight on the basis of a variety of reference percentiles based on $\mathrm{BMI}$ in various populations ${ }^{15}$.

The purpose of this study is to investigate whether an association between normal, overweight and obesity BMI and blood pressure values could be detected in children in the paediatric primary care practice as childhood BP is together with the changes in the BMI is a predictor of adult blood pressure ${ }^{4,16}$. The emphasis is to determine whether a relationship could be formed for young children as well as in children within the normal BMI\% group.

\section{Materials and Methods}

This study has been carried out on secondary data gathered from children between the ages of 6 and 14 years seen during weekly public screening days at Kocaeli Metropolitan Municipality Maternity and Children Hospital in Kocaeli, Turkey during the year 2002.

During the public screening, history of every child was taken by doctors. Children who already suffered major disorders (cardiac, respiratory, renal or haematological disorders) were not considered in this study. The medical examination of the children was carried out by a doctor in a quiet, comfortable and warm polyclinic room.

Heights and weights of children with shoes off and least possible clothes were measured. Measurements taken were the children's height in centimeters $(\mathrm{cm})$ and weight in kilograms (kg). Height was measured with a stadiometer in centimetres $(\mathrm{cm})$ attached to the wall.

Children were rested for fifteen minutes before their blood pressure measurements. Blood pressure was measured with the child in a seated position according to paediatric measurement guidelines ${ }^{17}$ by auscultation with an appropriate-size cuff and an aneroid sphygmomanometer. The fifth Korotkoff sound was used to determine diastolic blood pressure. Three blood pressure measurements were taken with three minutes intervals and the average value of these three measurements was recorded. Blood pressure, height and weight were always measured by the same doctor to ensure uniformity of recording.

Body mass index (BMI) $\left(\mathrm{kg} / \mathrm{m}^{2}\right)$ was calculated from the ratio of weight/height ${ }^{2}$. Sex and age specific BMI percentiles (\%) were calculated for each child using Centres for Disease Control and Prevention (CDC) 2000 reference values ${ }^{14}$. The children were then divided into three groups as normal, overweight and obese. Those with a BMI percentile (BMI \%) of less than $85^{\text {th }}$ percentile $(<85 \%)$ were put into normal group, those between $85^{\text {th }}$ and $95^{\text {th }}$ percentile $(\geq 85 \%-<95 \%)$ as overweight and $95^{\text {th }}$ percentile or more than $95^{\text {th }}$ percentile ( $\geq 95 \%)$ as obese.

Children were compared with respect to $\mathrm{BMI}$ and $\mathrm{BMI} \%$ The systolic blood pressure (SBP) and diastolic blood pressure (DBP) values of the children in each $\mathrm{BMI} \%$ groups were also compared with BMI values in the other groups. In addition, the correlation of SBP and DBP with BMI was evaluated in all BMI\% groups including normal BMI\% group, adjusted for age.

Statistical evaluation of the results was performed with the SPSS14 computer program using simple multiple linear regression. All significance tests were based at the 0.05 level of significance.

\section{Results}

One thousand and eighth hundred ninety nine (1899) children (male/female ratio=1033/866) with a mean age $9.52 \pm 2.62$ years were enrolled in the present study. Normal, overweight and obese BMI\% were called group 1, 2 and 3 respectively and this notation will be adopted in the rest of this paper. The mean and standard deviation of systolic and diastolic blood pressure values in each $\mathrm{BMI} \%$ group and BMI were also calculated and compared.

The number of children, male/female ratio, mean age, weight and height, BMI, SBP and DBP of each group are shown in Table 1 . It shows that BMI, SBP and DBP have increased from normal to obese group and mean age in each $\mathrm{BMI} \%$ groups are similar. 
Table 1: Mean age, weight, height, BMI, SBP, DBP and M/F of $\mathrm{BMI} \%$ groups (normal, overweight and obese).

\begin{tabular}{|l|c|c|c|} 
& $\begin{array}{c}\text { Normal BMl\% } \\
(n=1693) \\
\text { Mean } \pm \text { SD }\end{array}$ & $\begin{array}{c}\text { Overweight BMI\% } \\
(n=147) \\
\text { Mean } \pm \text { SD }\end{array}$ & $\begin{array}{c}\text { Obese BMI\% } \\
(n=59) \\
\text { Mean } \pm \text { SD }\end{array}$ \\
\hline Age(years) & $9.48 \pm 2.61$ & $10.14 \pm 2.69$ & $9.06 \pm 2.58$ \\
\hline M/F & $911 / 782$ & $89 / 58$ & $33 / 26$ \\
Weight(kg) & $29.33 \pm 10.42$ & $41.79 \pm 14.23$ & $42.55 \pm 16.12$ \\
\hline Height(cm) & $132.04 \pm 16.02$ & $138.71 \pm 16.88$ & $132.99 \pm 16.39$ \\
BMI & $16.24 \pm 2.07$ & $20.88 \pm 2.54$ & $23.13 \pm 3.54$ \\
\hline SBP & $93.16 \pm 13.37$ & $97.65 \pm 13.69$ & $98.81 \pm 15.54$ \\
\hline DBP & $60.72 \pm 9.40$ & $64.51 \pm 8.41$ & $64.57 \pm 10.52$ \\
\hline
\end{tabular}

SBP and DBP were compared among normal, overweight and obese groups see Table 2. Simple multiple linear regression was used including age factor in a linear Model 1 (Formula $=\mathrm{SBP} \sim$ age + factor $(\mathrm{BMI} \%)$ and Formula $=\mathrm{DBP} \sim$ age + factor $(B M I \%))$. It is a significant factor for SBP and DBP to adjust for BMI\% groups. There was a statistically significant increase in both SBP $(P \leq .001)$ and DBP $(P<001)$ that corresponded with increasing $\mathrm{BMI} \%$ category. SBP and DBP values were significantly higher in the obese group compared with the overweight and normal BMI\% group and also overweight higher than normal group see Table 2 .

Simple multiple linear regression was used including age factor in a linear Model 2 (Formula $=$ SBP $\sim$ age + factor (BMI) and Formula $=\mathrm{SBP} \sim$ age + factor $(\mathrm{BMI}))$. P-values are found to be statistically significant $<.001$. This means that, SBP and DBP values have increased with increasing BMI values as given in Table 2 .

Table 2: SBP and DBP are compared for BMI\% groups and BMI in linear regression model 1 and model 2 including age (Entered variables are $\beta$ : regression coefficient; BMI\%)

\begin{tabular}{|c|c|c|c|c|}
\hline Entered variable & $\beta$ & $\mathrm{t}$ & $p$ & Adjusted $\mathrm{R}^{2}$ \\
\hline \multicolumn{5}{|l|}{$\begin{array}{|ll|}\text { Systolic } & \text { blood } \\
\text { pressure } & \\
\text { Model 1 } & \\
\end{array}$} \\
\hline Age (years) & 0.466 & 23.01 & $<.001$ & \multirow{4}{*}{0.235} \\
\hline Normal BMI\% & 0.072 & 3.20 & 0.001 & \\
\hline Overweight BMI\% & 0.081 & 3.68 & $<.001$ & \\
\hline Obese BMI\% & 0.079 & 3.79 & $<0.001$ & \\
\hline \multicolumn{5}{|l|}{ Model 2} \\
\hline Age (years) & 0.378 & 15.58 & $<0.001$ & \multirow[b]{2}{*}{0.246} \\
\hline BMI & 0.171 & 7.06 & $<0.001$ & \\
\hline \multicolumn{5}{|l|}{$\begin{array}{ll}\text { Diastolic } & \text { blood } \\
\text { pressure } & \\
\text { Model 1 } & \end{array}$} \\
\hline Age (years) & 0.439 & 21.44 & $<0.001$ & \multirow{4}{*}{0.219} \\
\hline Normal BMI\% & 0.090 & 3.97 & $<0.001$ & \\
\hline Overweight BMI\% & 0.107 & 4.78 & $<0.001$ & \\
\hline Obese BMI\% & 0.098 & 4.67 & $<0.001$ & \\
\hline \multicolumn{5}{|l|}{ Model 2} \\
\hline Age (years) & 0.350 & 14.21 & $<0.001$ & \multirow[b]{2}{*}{0.225} \\
\hline BMI & 0.179 & 7.26 & $<0.001$ & \\
\hline
\end{tabular}

SBP and DBP have shown a graded, statistically significant increase from normal weight to obese children. After adjustment for age, BMI, normal, overweight, obese BMI\% SBP and DBP differences remained statistically significant at $P<0.05$.

$\mathrm{BP}$ is increasing with increasing BMI in all age groups and this could be detected in young children. Fig.1a and Fig.1b show mean DBP and SBP values with respect to age. It can be seen that $\mathrm{BP}$ is increasing with increasing $\mathrm{BMI}$ values even in normal group but the increase is more in obese children.

Figure 1: Mean values of a) systolic blood pressure and b) diastolic blood pressure according to the BMI\% groups (normal, overweight, obese) [1= normal (BMI\% <85\%), 2=

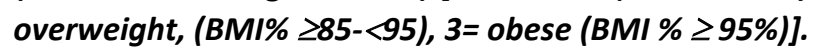

Figure $1 b$
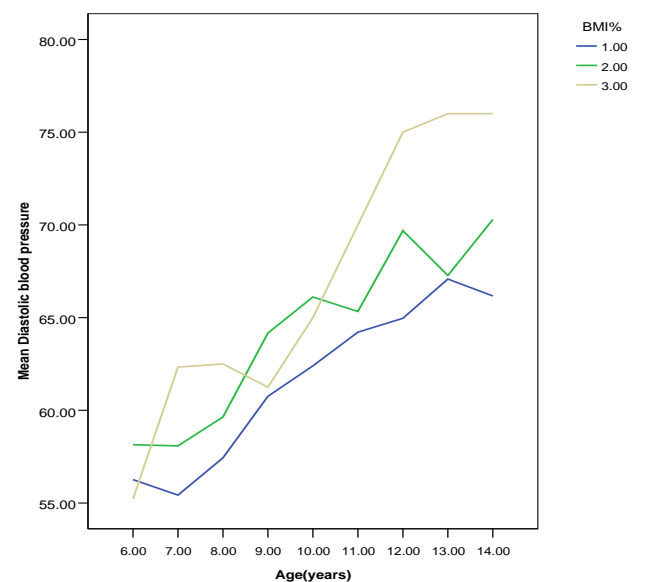

Figure $1 b$

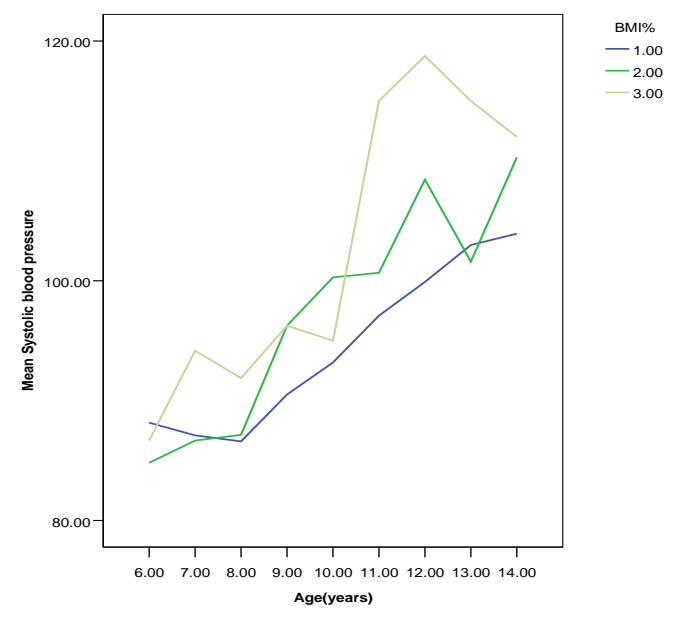

\section{Discussion}

Childhood obesity has been attracting more attention because of the concerns of its long-term effects in adulthood. The first examination of the data shows that $7.7 \%$ of children out of 1899 have $\mathrm{BMI} \% \geq 85^{\text {th }}-<95^{\text {th }}$ and $3.1 \%$ of the children have $\mathrm{BMI} \% \geq .95^{\text {th }}$. 
Burke et al. ${ }^{18}$ recently described an independent association between high BP and IOTF-defined overweight and obesity, in a prospective study carried out in an Australian cohort of children followed-up from the age of 9 to 25 year old, as did Genovesi et al. ${ }^{19}$ in a cross-sectional study carried out in a sample of school children living in northern Italy. It is reported in the study of Sorof et al. ${ }^{5}$ that, among all demographic and clinical factors analyzed, BMI was most strongly associated with hypertension. Mirza et $\mathrm{al}^{20}$ found that mean SBP was significantly higher in overweight children.

Our results show that the mean difference of both SBP and DBP between the matched BMI was found to be significant $(P<0.05)$ in early life. Moreover, there is an impact of childhood BMI on BP in the normal BMI\% group children. An increase in adjusted $\mathrm{BMI}$ and $\mathrm{BMI} \%$ can then be associated with an increase in SBP and DBP in children.

In addition, our data has shown that there is a significant association between BMI and BP in all age groups (6-14 years old) even in young children. Compared with children with $\mathrm{BMI} \%<85^{\text {th }}$, both SBP and DBP values are higher in children with $\mathrm{BMI} \% \geq 85$ th and $<95$ th and were highest in children with $\mathrm{BMI} \% \geq 95$ th in $6-14$ years. Falkner et al. ${ }^{8}$ have reported the same trend in all age groups they considered. Reinerh et $\mathrm{al}^{1}$ reported that children older than 12 years had a slightly increased risk of hypertension probably reflecting the influence of duration of obesity.

Furthermore, it can be seen that BMI is also increasing for normal children. This important finding was also reported in the study of $\mathrm{He}$ et al. and raises the question of how to define childhood obesity should it be based on a functional outcome such as BP or on a statistical cut-off point of a population-based BMI distribution as stated in the study of He et al. ${ }^{4}$.

\section{Conclusion}

Our results show that $\mathrm{BMI}$ is associated with elevated SBP and DBP in overweight and obese children. BP is increasing with increasing $\mathrm{BMI}$ values even in normal group but the increase is more in obese children. This is an important and interesting finding and was reported in the literature once before. These results also suggest that careful monitoring of age related normal growth increase in the BMI in childhood and tackling and keeping it within the normal limits is important in preventing higher BP values and related health problems later in life.

\section{Acknowledgements}

We would like to thank $\mathrm{Dr} \mathrm{N}$ Hunter of Health Protection Agency, Didcot, Oxon, UK, for all the advice and help given on statistics.

\section{References}

1. Reinehr T, Andler W, Denzer C, Siegried W, Mayer $\mathrm{H}$, Wabitsch M. Cardiovascular risk factors in overweight German children and adolescents: relation to gender, age and degree of overweight. Nutr Metab Cardiovasc Dis2005;15(3):181-7.

2. Field $A E$, Cook NR, Gillman MW. Weight status in childhood as a predictor of becoming overweight or hypertensive in early adulthood. Obes Res 2005. 13:163-9.

3. Cole TJ, Bellizzi MC, Flegal KM, Dietz WH. Establishing a standard definition for child overweight and obesity worldwide: international survey. BMJ 2000;320(7244):1240-3.

4. He Q, Ding ZY, Fong DY, Karlberg J. Blood pressure is associated with body mass index in both normal and obese children. Hypertension2000;36:165-70.

5. Sorof J, Daniels S. Obesity hypertension in children: a problem of epidemic proportions. Hypertension 2002; 40(4): 441-7.

6. Changing History. The World Health Report 2004. Geneva. World Health Organization. 2004. http:// www.who.int/whr/2004/en/report04_en.pdf

7. Sorof JM, Lai D, Turner J, Poffenbarger T, Portman RJ. Overweight, ethnicity, and the prevalence of hypertension in school-aged children. Pediatrics 2004; 113(3):475-82.

8. Falkner B, Gidding SS, Ramirez-Garnica G, Armatti Wiltrout S, West D, Rappaport EB. The relationship of body mass index and blood pressure in primary care pediatric patients. J Pediatr 2006; 148(2):195200.

9. Urrutia-Rojas X, Egbuchunam CU, Bae S, Menchaca J, Bayona M, Rivers PA, et al. High blood pressure in school children: prevalence and risk factors. BMC Pediatrics 2006;6:32.

10. Frontini MG, Bao W, Elkasabany A, Srinivasan SR, Berenson G. Comparison of weight-for-height indices as a measure of adiposity and cardiovascular risk from childhood to young adulthood: The Bogalusa heart study. J Clin Epidemiol 2001; 54(8):817-22.

11. Clinical Practice Guidelines for the Management of Overweight and Obesity in Children and Adolescents Endorsed 18 September 2003; website: www.obesityguidelines.gov.au

12. Barba G, Troiano E, Russo P, Strazzullo P, Siani A. Body mass, fat distribution and blood pressure in Southern Italian children: results of the ARCA project. Nutr Metab Cardiovasc Dis 2006 16(4):23948.

13. Will B, Zeeb H, Baune BT. Overweight and obesity at school entry among migrant and German children: a cross-sectional study. BMC Public Health 2005; 5:45.

14. Kuczmarski RJ, Ogden CL, Guo SS, Grummer-Strawn LM, Flegal KM, Mei Z, et al. 2000 CDC Growth Charts for the United States: methods and development. Vital Health Stat 112002 ;(246):1190.

15. Flegal KM, Ogden CL, Wei R, Kuczmarski R, Johnson 
CL. Prevalence of overweight in US children: comparison of US growth charts from the Centers for Disease Control and Prevention with other reference values for body mass index. Am J Clin Nutr 2001; 73:1086-93.

16. Iman S, Hind A-H, Ali A, Farida M, Bayoomi A, AlBatish $M$. Juvenile Hypertension in Kuwait: Prevalence and Influence of Obesity. International Pediatrics 2003; 18:3.

17. National High Blood Pressure Education Program Working Group on Hypertension Control in Children and Adolescents: Update on the 1987 Task Force Report on High Blood Pressure in Children and Adolescents: a Working Group report from the National High Blood Pressure Education Program. Pediatrics. 1996 98:649-658.

18. Burke V, Beilin LJ, Dunbar D, Kevan M. Associations between blood pressure and overweight defined by new standards for body mass index in childhood. Prev Med 2004; 38(5):558-64.

19. Genovesi S, Giussani M, Pieruzzi F, Vigorita F, Arcovio C, Cavuto S, et al. Results of blood pressure screening in a population of school-aged children in the province of Milan: role of overweight. J Hypertens 2005; 23(3):493-7.

20. Mirza M, Nazrat M, Kadow K, Palmer M, Solano $H$, Rosche C, Yanovski JA. Prevalence of overweight among inner city Hispanic-American children and adolescents. Obes Res 2004; 12(8): 1298-310. 